\title{
Automating lecture capture using Opencast
}

\author{
Daniel Ebbert ${ }^{1}$ \\ 'University of Münster, Georgskommende 25, 48143 Münster, Germany daniel.ebbert@uni- \\ muenster.de
}

Keywords

lecture recording, Opencast, automation, lecture capture

\section{ABSTRACT}

Lecture recordings are being used more and more by universities. To be able to achieve a high coverage of recorded lectures this process needs to be automated. At the University of Münster this is being done by using Opencast in combination with fixed recording equipment in the lecture halls. The lectures are being recorded automatically and most of the video processing is automated as well. Although, not the whole work process is automated yet, there are ways to make this possible in the future by connecting a learning management system or a campus management system.

\section{INTRODUCTION}

The use of lecture recordings is more and more common. They are well received by students and are considered very useful among the students at the University of Münster (Dageförde, Marek, \& Reischmann, 2016). The University of Münster is using Opencast to record lectures and in the following it is described why and how this has been implemented at the University of Münster. Section 3 covers the reasoning why one would want to record lectures and why it is desirable to automate this process. This is followed by section 4 in which some background information is provided about the lecture recording system used at the university of Münster and how it has been implemented. Section 5 then covers how the different parts of the lecture recording process have been automated followed by what still needs to be automated. Next, the sections 6 and 7 are about the usage of the lecture recordings and how the lecture recording service has been perceived by the students as stated in the evaluation. Lastly a short summary is given.

\section{RELATED WORK}

This section analyses usage scenarios, benefits and drawbacks identified from related work. The literature shows that the practice of recording lectures is becoming more common at universities. The way this has been implemented and is being used differs a lot. However, it is usually positively received by the students. Bennett \& Glover (2008) reports that $91 \%$ of the surveyed students stated that lecture recordings assist their learning.

For the usage of lecture recordings there are multiple scenarios. The two main use cases are the reviewing of the lectures with the recordings for better understanding and the usage of the recordings to prepare for exams. Possible other scenarios could be to use lecture recordings to provide additional material to ambitious students (Montrieux, Vangestel, Raes, Matthys, \& Schellens, 2015), or to flip the classroom and have the students watch the recordings at home and use the time with the students for exercises or questions from students (Makarem, 2015).

Zupancic and Horz (2002) identified three usage groups among their students. These are:(1) students who do not use the lecture recordings, (2) students who occasionally use the lecture recordings and (3) students who make intense use of the recordings (Zupancic \& Horz, 2002). While intense users of the lecture recordings always watch the full recording, occasional users sometimes just watch parts of a recording (Tillmann, Bremer, \& Krömker, 2012). Additionally, students are stating that they prefer to watch a video to prepare for a lecture over reading a text (Woodruff, Jensen, Loeffler, \& Avery, 2014). 
The observation that lecture recordings are not always fully watched is connected to the usage of the recordings by the students and how much attention they are spending on it. While lecture recordings are watched in full during exam preparation they are not always needed in full length, in some cases a short part or a summary can be enough (Van Zanten, Somogyi, \& Curro, 2012). Advantages that are often cited by students are that lecture recordings allow them to determine their own learning speed (Tillmann, Niemeyer, \& Krömker, 2014) and that they are able to review missed lectures (Rust \& Krüger, 2011). Especially for students who are not able to attend many lectures the lecturer recordings are of value (Wieling \& Hofman, 2010). For them the recordings make it easier to have a job while studying (Tillmann et al., 2012) or to take care of ones family (Rust \& Krüger, 2011).

Being able to review difficult parts of a lecture is being perceived as helpful and leads to more students passing the course (López-Pérez, Pérez-López, \& Rodríguez-Ariza, 2011; Montrieux et al., 2015; Zimmermann, Jokiaho, \& May, 2011). Especially students, who otherwise would have failed, benefit from the lecture recordings (Zimmermann et al., 2011). In addition, a frequent use of the lecture recordings can lead to a positive change in course performance (Whitley-Grassi, 2017).

The possibility to watch lecture recordings influences attendance less than often assumed. According to Zimmermann et al. (2011) some students state that they use the lecture recordings as an alternative to attending the lectures, although the number of students who attended the lecture in this study did not decrease. Others like Tillmann et al. (2012) state that among occasional users of lecture recordings the attendance dropped by $12 \%$ and for intensive users by $20 \%$ while Leadbeater, Shuttleworth, Couperthwaite, \& Nightingale (2013) reported a general decrease in attendance by $\sim 15 \%$.

As Nagai (2009) stated there are three parts to lecture recording, pre-processing, recording and post-processing. The pre-processing usually consists of getting in contact with the lecturers, getting consent to record and schedule the recordings to be recorded either manually or by a computer. The recording phase usually consists of setting up the recording equipment and actually recording the lecture while post-processing usually consists of uploading, editing, and publishing the recording. Of these parts the most labour intensive part is the recording (Nagai, 2009). In the following, the recording part is described in more detail.

The traditional way of making a recording is to show up somewhere with a camera and simply point the camera at whatever needs to be recorded. Although, in the context of lecture recording more is required then just a video of the lecturer. Additionally, it is relevant to also record whatever is shown on a beamer, in most cases the presentation, along with the video and audio of the lecturer (Stolzenberg \& Pforte, 2007). There are two approaches to also getting the relevant information shown on the beamer. The first approach is to record one video signal with a wide range that covers the lecturer as well as the content shown on the beamer. In the second approach only the lecturer is filmed and the beamer is recorded separately, which leads to a higher quality recording.

If the choice is made to record the beamer signal separately there are two ways to achieve this. One can record the input document with a symbolic recorder application or one can record the output document as it is shown on the beamer with a screen recorder (Ziewer, 2007). Recording the input document refers to running the recording software on the same computer as the content to be recorded, for example by using a plugin to Microsoft PowerPoint and getting the slide text as well as the slide change events directly from Microsoft PowerPoint. This has the advantage that it provides additional metadata about the recording that can be accessed while playing the recording. However, it has the disadvantages that it is limited to presentation software that is supported by the recording software and that it is prone to human error (Ziewer, 2007).

Recording the output document can be done by external devices, such as a video grabber, which records everything that is being send from the presentation computer to the beamer. This has the advantages that it is not tied to the recording software and is not prone to human error as it works independently of the presenters computer. The lecturer can also use other programs to show information to the students. However, this causes the drawback that extra information, such as text on the slides, needs to be extracted while processing the recording (Ziewer, 2007).

With the recording of the presentation separated from the recording made by the camera it is possible to focus on recording the presenter and the audio. Nevertheless, the recording of the presenter is of less importance than the recording of the presentation and the audio. However, it is 
still needed as it makes the recording more engaging for the students and helps to keep concentrated while watching the recording (Kizilcec, Papadopoulos, \& Sritanyaratana, 2014). Therefore, it is desirable to keep the presenter in focus. This can be accomplished during the recording, by having a person standing behind a camera in a lecture or automatically by using PTZ cameras in combination with tracking software like LectureSight (Wulff \& Fecke, 2012) or by using cameras with included digital tracking, as for example provided with some Axis cameras (Axis Communications $A B, 2017)$. During post-processing it can also be accomplished by analysing the movements within a recorded video and rendering a tracking version of it, an example of this kind of software is Track4K (University of Cape Town, 2016).

It is debatable whether the manual recording approach or the automatic recording approach result in recordings of better quality, which is also depending upon the usage scenarios of these recordings. The consideration of manual or automatic recording comes down to the following three arguments: (1) how likely are human errors, (2) what are the costs and (3) how well does it scale.

On the one hand, the manual recording approach is quite prone to human errors as there are many possible error sources. These could cause an error every time a lecture is recorded. Such sources are, for instance, setting up the camera correctly, configuring the presentation software and recording software to interact correctly, or having to plug in the video grabber correctly. To guarantee the success of a recording, a member of the recording team has to transport the recording equipment to the lecture hall, set up the recording equipment, record the lecture and afterwards pack the recording equipment again. Considering the amount of work that needs to be done manually a 90 minutes lecture recording can easily amount to up to 2.5 hours of work. This might be feasible when the number of recordings per week is relatively low and while there are only a few recordings at the same time. Once there are multiple recordings in parallel in different locations the personnel required to cope and the resutling costs would increase a lot (Nagai, 2009), which most universities just cannot afford (Mertens \& Rolf, 2003). Thus, the manual recording approach is not scalable.

On the other hand, the automatic recording approach is not prone to errors as the whole process of recording takes place automatically using recording devices equipped with video grabbers and cameras that track the presenter. Once the initial setup is done no manual interaction is needed. This requires more work to get started but leads to less errors in the long run. Since no personnel has to be present for the recording, the number of people working on lecture recording is lower then in the manual recording approach. This also means that adding another lecture hall does not automatically has to lead to an increase in personnel. This, therefore, means lower costs and a better ability to scale. This is described in more detail in section 5 .

\section{TECHNICAL SETUP}

The University of Münster started lecture recording in the summer of 2014, although only on a small scale. Based on the positive feedback from the students the General Students' Committee requested a centrally funded project aimed at lecture recording in June 2015 (Allgemeiner Studierendenausschuss der Universität Münster, 2015). This was approved in July 2015 and the lecture recording project started in November 2015. The aim of this project is to have up to 20 lecture halls equipped with lecture recording technology until the end of 2017. Considering the aim of the project and the size of the University of Münster a few requirements for the lecture capture system were drawn up. These included the ability to:

- record automatically based on a schedule,

- publish recordings automatically to a predefined destination,

- record more than 2 sources at the same time in high definition,

- play back more than 2 sources at the same time,

- host the server infrastructure on university servers,

- scale the server infrastructure as needed,

- define the video processing workflow,

- integrate learning management systems. 
Based on these requirements the lecture capture solutions Opencast (Apereo Foundation, 2016), Kaltura (Kaltura Inc., 2016), Panopto (Panopto, 2017) and MediaSite (Sonic Foundry Inc., 2017) were compared. The main reasons for choosing Opencast were that it can be hosted on university servers and can easily be scaled. Furthermore, it allows us to work with a wide range of capture agents.

Opencast was initiated by 13 institutions from North America and Europe to develop a web based open source system aimed at automating lecture recording that would meet common requirements (Ketterl, Schulte, \& Hochman, 2010). Opencast runs on Linux which enabled us to choose a fast and lightweight container runtime, Docker. This allows to put the focus on the applications and not the machines. Additionally, the running behaviour can be easily reproduced which makes testing easier.

Concerning the capture agents, there are quite a few capture agents on the market, as shown in a comparison by Burriel \& Dechter (2016). However, none of the capture agents on the market offer the needed flexibility in configuration and remote maintenance that we need in a diverse and wide spread teaching environment as we have at the University of Münster. Therefore, we chose to make custom capture agents, which can be adapted to each specific lecture hall. The capture agents are running on Linux as well and use pyCA (Kiesow, 2017) as the capture agent software. Furthermore, our custom capture agents have baseboard management controllers which allows for complete remote maintenance.

Principles for the successful implementation of lecture recordings in higher education have been published by Ollermann, Rolf, Greweling, \& Klaßen (2017). Upon designing our lecture recording system we were not aware of these principles. However, we were in contact with one of the authors and also use Opencast. This resulted in our lecture recording system being similar and following some of the described principles. Especially the described principles of efficiency, flexibility, usability, compatibility and high coverage have been applied while some work is still needed concerning the principles of integration, autonomy and reliability.

\section{AUTOMATION}

Once the lecture capture system is set up one can start automating the recording process. As previously stated there are three phases to the lecture recording process, (1) pre-processing, (2) recording and (3) post-processing (Nagai, 2009). In the pre-processing phase the first step is to contact the lecturers and get their consent for the recordings, which is done manually. Once the lecturers give their consent the integration of the course in learning management system and the series in Opencast can be set up, this is done manually as well.

Following the efficiency principle of Ollermann et al. (2017) the automation process starts with the scheduling of the events to be recorded. At the beginning of the semester the lectures that are to be recorded are scheduled in the lecture capture system. This means that the lecture capture system, in this case Opencast, manages which capture agent has to record which signal at which time. This recording schedule is transferred from Opencast to the capture agents.

The recording phase starts with the capture agent starting to record according to the schedule provided by Opencast. Our capture agents can record four signals at the same time, depending on the wishes of the lecturer. These are: the audio and beamer signal provided by the media-controldevices installed in the lecture hall as well as two camera streams provided by an Axis network camera, one being the full view of the lecture hall and the other being a digital autotracking video (Axis Communications AB, 2017). During the recording the lecturer can hold the lecture as he or she is used to without having to change anything because of the recording. This can be achieved by recording the video signal that goes to the beamer and the audio signal of the microphone that the lecturer uses anyway, as described in the flexibility principle (Ollermann et al., 2017).

The post-processing phase starts with the capture agent automatically uploading the recording to the Opencast server. The Opencast server then starts processing the recording according to a previously defined routine, a so called workflow. After the initial processing is done the recording can be edited and trimmed. Afterwards the processing continues on the Opencast server, again according to a previously defined workflow. After processing the recording is automatically published to the previously configured course in the learning management system, which increases the usability as the interface of the learning management system is already know to the users, according to the usability principle (Ollermann et al., 2017). If it is requested by the lecturer a control step can be added before the recording is published to the learning management system. Using the 
learning management system the students then can access the Opencast player, a HTML5 player which delivers MPEG4/H.264 encoded video to the user, as stated in the compatibility principle (Ollermann et al., 2017).

So at the moment, the only operations that need to be executed manually are (1) notifying the lecturers and getting consent to record from the lecturers, (2) the scheduling of the recordings, (3) the integration into the learning management system, which only needs to be done once per course in the pre-processing phase, and (4) the editing of the recordings which needs to be done for every recording in the post-processing phase. The most labour intensive part of the lecture recording process, the recording, is already fully automated.

This however, is still quite a lot of work that needs to be done manually if one takes into account that the aim of this project is to record up to 20 lecture halls till the end of 2017, and possibly more after that. Most of the work that still needs to be done to further automate our work processes concerns the principles of integration, autonomy and reliability (Ollermann et al., 2017). At the moment, entering the metadata about the recordings and the scheduling is being done manually, which could be done automatically as described by Ollermann et al. (2017) using a plugin in the learning management system or by connecting a campus management system to Opencast as it has been done by the University of Manchester (Schiebeck, 2017).

Concerning the connection to the learning management system to achieve higher autonomy, as described in the autonomy principle (Ollermann et al., 2017), some work needs to be done as well. While there is a plugin for Stud.IP which gives as much control as feasible to the lecturer, such a plugin for Moodle, which is used as the central LMS in Münster, does not exist yet. Although, it is under development.

As for the reliability principle (Ollermann et al., 2017), we do not have backup recording systems yet, although we do monitor our devices and only had two failed recordings in the winter term 2016/17. One recording failed because of connectivity issues and the second recording failed because the audio signal was not provided by the media-control-device in the lecture hall. We seek to minimize the risk of human error because in our case the metadata still needs to be entered manually, which again could be solved by either a close integration with the learning management system or a campus management system, or both.

Lastly, as described in the high coverage principle (Ollermann et al., 2017), we try to achieve a high coverage so as to reach as many students as possible. At the time of writing we equipped 13 lecture halls with recording systems and more are in planning. However, all lecturers whose classes take place in the equipped lecture halls are still being contacted manually and asked if they want to participate. This limits the possible coverage to the classes of lectures who want to be recorded. Another approach to this is to move from an opt-in approach to an opt-out approach, like it is being done by the University of Manchester (Phillipson, 2017), where all lectures are being recorded by default. There is an increasing move towards an opt-out approach according to Rios-Amaya, Secker, \& Morrison (2016).

\section{ANALYTICS}

Once the recordings are made, included in the LMS and made available for the students the first question that often comes up is whether the students are actually watching the recordings. In Opencast 2.x some data is already being collected via a user tracking service in the player, although it only tracks the number of hits per recording. This however, is already enough to gain some insight into the usage of the recordings as Ebbert (2017) demonstrates. Lectures were given from the $17^{\text {th }}$ of October 2016 until the $10^{\text {th }}$ of February 2017 with the exams taking place shortly after the last lecture and the semester ending on the $31^{\text {st }}$ of March 2017. The usage over the first few month of the semester is comparable and as soon as it is time for the exams the usage increases as expected, as shown in figure 1 . The end of the lecture time, the $10^{\text {th }}$ of February 2017 is marked in figure 1 with a red line. Starting after the holidays around new years eve the number of hits on the provided recordings increases till the end of the lecture time, then drops and increases again in the end of February. The statistics for single lecture series show similar usage patterns as the overall usage of all recordings.

Although the information gained using the user tracking endpoint in Opencast $2 . x$ can already be quite interesting, it I still quite limited. One way to solve this is by integrating Piwik into the 
Opencast player, which has been implemented by Rolf (2017). This makes it possible to track how often a video has been played and paused, at which quality and playback rate it has been watched and whether the users made use of the zoom function or not. This functionality will be included in Opencast 3.0 and should provide administrators with additional information as to how the students interact with the provided recordings. However, it does not yet provide information about which parts of the video have been watched and how many times those have been watched, which could be used to identify potentially difficult parts of the lecture recordings. This could possibly be done using the Media Analytics plugin for Piwik provided by Innocraft Ltd. (2017).

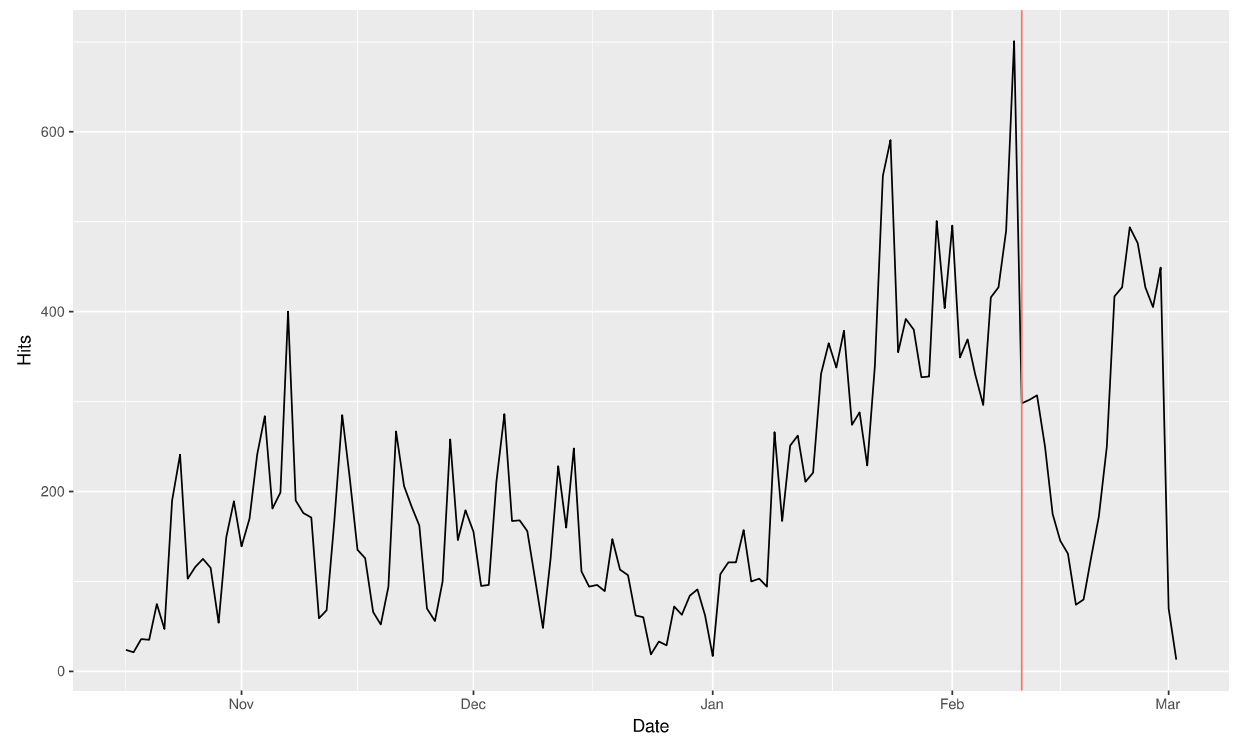

Figure 1: Hits on lecture recordings over the winter term 2016/17, the red line representing the last lecture given (Ebbert, 2017)

\section{EVALUATION}

At the end of the semester, the lecture recording service was evaluated among the students who had access to it. The data collection for the evaluation took place by means of a survey which the students had access to via the learning management system. The survey was open from the $29^{\text {th }}$ of January 2017 till the $21^{\text {st }}$ of February 2017.

The results of this evaluation were especially of interest in terms of the reported usage as well as the subjective quality of the recordings. Most of the students stated to have watched nearly every recording, sometimes even multiple times. If they watched the recording they usually watched the whole recording. Reasons for doing so were that the recorded lectures covered difficult topics and the students were reviewing the lectures in order to better understand what was said. For this purpose they usually watched the full recording.

About half of the students stated that they attended less lectures because they could expect to have access to a recording afterwards. The reasons for doing so according to the students were mainly so that they could learn at their own pace but also because they had to work or were sick. Additionally, the students stated that the recordings support them in their learning progress, especially before the exams.

The part of the lecture recording of which the quality was of the most importance to the students was the sound quality, followed by the quality of the slides and lastly the quality of the video of the lecturer. All in all the students were satisfied with the provided service and wish that the lecture recording service is going to be extended to cover more lecture halls and lectures given (Ebbert, Marek, \& Paulus, 2017). 


\section{SUMMARY}

To summarize, providing lecture recordings is well received and sometimes even expected by students. Lecture recordings can assist students in their learning as it gives students more flexibility to study at their own pace, to review missed lectures or difficult parts (Ebbert et al., 2017) and to make it easier for students to have a job while studying (Tillmann et al., 2012). The attendance drops by $12 \%$ to $20 \%$ according to (Tillmann et al., 2012) although the number of students passing their courses can go up (López-Pérez et al., 2011; Montrieux et al., 2015; Zimmermann et al., 2011).

There a a few lecture recording solutions on the market and at the University of Münster we chose to use Opencast as we want to automate as much of the lecture recording process as possible. This is being done by using fixed recording equipment in the lecture halls and scheduled recordings. This way, the recordings can be scheduled in advance and the recording takes place automatically. After the recording the video files are automatically uploaded and processed. Cutting the recording takes place manually and afterwards the recordings are also automatically published to the LMS.

What still needs to be done manually is getting consent from the lecturers, setting up the LMS integration per course and scheduling the recordings as well as cutting every recording. Although, there are ways in which this can also be automated. For example by connecting a LMS plugin or a campus management system that provides the metadata and schedule for the recordings. The cutting of the recordings can possible be outsourced to the lecturers or their assistants.

The students used the recordings as expected and stated in the evaluation that they were satisfied with the provided service. Most of the students stated to have watched entire recordings and the recordings were also used as expected, to review difficult parts or whole lectures and in preparation for the exams.

\section{REFERENCES}

Allgemeiner Studierendenausschuss der Universität Münster. (2015). Antrag auf Ausbau von Vorlesungsaufzeichnungen aus QVMs. Münster.

Apereo Foundation. (2016). Opencast. Retrieved March 20, 2017, from http://www.opencast.org/

Axis Communications AB. (2017). AXIS Digital Autotracking. Retrieved May 10, 2017, from https://www.axis.com/be/nl/products/axis-digital-autotracking

Bennett, P. N., \& Glover, P. (2008). Video streaming: Implementation and evaluation in an undergraduate nursing program. Nurse Education Today, 28(2), 253-258. http://doi.org/10.1016/j.nedt.2007.04.005

Burriel, R., \& Dechter, C. (2016). Evaluation of Lecture Capture Appliances. Corvallis, Oregon, USA. Retrieved from http://blogs.oregonstate.edu/streaming/files/2016/06/lecture-capturereport.pdf?pdf=lecturecapture\&s=wordpress

Dageförde, J., Marek, M., \& Reischmann, T. (2016). Learnweb Evaluationsbericht 2016. Münster.

Ebbert, D. (2017). Video usage analysis in R. Retrieved May 2, 2017, from https://replay.teltek.es/opencast2017/video/58ac14a9a7bc28c9008b457f

Ebbert, D., Marek, M., \& Paulus, C. (2017). Auswertung der eLectures Evaluation. Münster.

Innocraft Ltd. (2017). Media Analytics. Retrieved May 2, 2017, from https://www.mediaanalytics.net/

Kaltura Inc. (2016). Kaltura. Retrieved March 20, 2017, from https://corp.kaltura.com/

Ketterl, M., Schulte, O. A., \& Hochman, A. (2010). Opencast Matterhorn. Interactive Technology and Smart Education, 7(3), 168-180. http://doi.org/10.1108/17415651011071631 
Kiesow, L. (2017). pyCA. Retrieved May 9, 2017, from https://github.com/opencast/pyCA

Kizilcec, R. F., Papadopoulos, K., \& Sritanyaratana, L. (2014). Showing face in video instruction: effects on information retention, visual attention, and affect. Proceedings of the 32nd Annual ACM Conference on Human Factors in Computing Systems, 2095-2102. http://doi.org/10.1145/2556288.2557207

Leadbeater, W., Shuttleworth, T., Couperthwaite, J., \& Nightingale, K. P. (2013). Evaluating the use and impact of lecture recording in undergraduates: Evidence for distinct approaches by different groups of students. Computers and Education, 61(1), 185-192. http://doi.org/10.1016/j.compedu.2012.09.011

López-Pérez, M. V., Pérez-López, M. C., \& Rodríguez-Ariza, L. (2011). Blended learning in higher education: Students' perceptions and their relation to outcomes. Computers \& Education, 56(3), 818-826. http://doi.org/10.1016/j.compedu.2010.10.023

Makarem, S. C. (2015). Using Online Video Lectures to Enrich Traditional Face-to-Face Courses. International Journal of Instruction, 8(2), 155-164. http://doi.org/10.12973/iji.2015.8212a

Mertens, R., \& Rolf, R. (2003). Automation Techniques for Broadcasting and Recording Lectures and Seminars. In SINNO3, Third International Technical Workshop and Conference.

Montrieux, H., Vangestel, S., Raes, A., Matthys, P., \& Schellens, T. (2015). Blending Face-to-Face Higher Education with Web-Based Lectures: Comparing Different Didactical Application Scenarios. Educational Technology \& Society, 18(1), 170-182.

Nagai, T. (2009). Automated lecture recording system with AVCHD camcorder and microserver. In Proceedings of the ACM SIGUCCS fall conference on User services conference - SIGUCCS '09 ( $\mathrm{p}$. 47). ACM Press. http://doi.org/10.1145/1629501.1629512

Ollermann, F., Rolf, R., Greweling, C., \& Klaßen, A. (2017). Principles of successful implementation of lecture recordings in higher education. Interactive Technology and Smart Education, 14(1), 2-13. http://doi.org/10.1108/ITSE-09-2016-0031

Panopto. (2017). Panopto. Retrieved March 20, 2017, from https://www.panopto.com/dach/

Phillipson, S. (2017). An overview of Lecture Capture at the University of Manchester. Retrieved May 3, 2017, from https://replay.teltek.es/opencast2017/video/58ab3a8ba7bc2880008b4575

Rios-Amaya, J., Secker, J., \& Morrison, C. (2016). Lecture Recording in Higher Education: Risky Business or Evolving Open Practice. Kent.

Rolf, R. (2017). MH-12117 Piwik tracking in Player. Retrieved May 2, 2017, from https://bitbucket.org/opencast-community/matterhorn/pull-requests/1420/mh-12117-piwiktracking-in-player/diff

Rust, I., \& Krüger, M. (2011). Der Mehrwert von Vorlesungsaufzeichnungen als Ergänzungsangebot zur Präsenzlehre. Wissensgemeinschaften: Digitale Medien- Öffnung Und Offenheit in Forschung Und Lehre, 229-239.

Schiebeck, T. (2017). Porting Participation Managent to Opencast 2.x. Retrieved May 13, 2017, from https://replay.teltek.es/opencast2017/video/58ac15a8a7bc283a008b4582

Sonic Foundry Inc. (2017). Mediasite Video Platform. Retrieved March 20, 2017, from http://www.sonicfoundry.com/mediasite/ 
Stolzenberg, D., \& Pforte, S. (2007). Lecture Recording: Structural and Symbolic Information vs. Flexibility of Presentation. The Electronic Journal of E-Learning, 5(3), 219-226.

Tillmann, A., Bremer, C., \& Krömker, D. (2012). Evaluationsergebnisse eines mehrperspektivischen Ansatzes Digitale Medien - Werkzeuge für exzellente Forschung und Lehre. Digitale Medien Werkzeuge Für Exzellente Forschung Und Lehre, 235-249.

Tillmann, A., Niemeyer, J., \& Krömker, D. (2014). “Im Schlafanzug bleiben können”. E-Lectures zur Diversifizierung der Lernangebote für individuelle Lernräume. Lernräume Gestalten Bildungskontexte Vielfältig Denken, 317-331.

University of Cape Town. (2016). Track4K. Retrieved May 9, 2017, from http://track4k.co.za/index.html

Van Zanten, R., Somogyi, S., \& Curro, G. (2012). Purpose and preference in educational podcasting. British Journal of Educational Technology, 43(1), 130-138. http://doi.org/10.1111/j.14678535.2010.01153.x

Whitley-Grassi, N. E. (2017). Evaluating Student Use Patterns of Streaming Video Lecture Capture in a Large Undergraduate Classroom. Walden University.

Wieling, M. B., \& Hofman, W. H. A. (2010). The impact of online video lecture recordings and automated feedback on student performance. Computers \& Education, 54(4), 992-998. http://doi.org/10.1016/j.compedu.2009.10.002

Woodruff, A. E., Jensen, M., Loeffler, W., \& Avery, L. (2014). Advanced screencasting with embedded assessments in pathophysiology and therapeutics course modules. American Journal of Pharmaceutical Education, 78(6), 128. http://doi.org/10.5688/ajpe786128

Wulff, B., \& Fecke, A. (2012). LectureSight - An Open Source System for Automatic Camera Control in Lecture Recordings. In 2012 IEEE International Symposium on Multimedia (pp. 461-466). IEEE. http://doi.org/10.1109/ISM.2012.94

Ziewer, P. (2007). Flexible and Automated Production of Full-Fledged Electronic Lectures. Technische Universiät München.

Zimmermann, M., Jokiaho, A., \& May, B. (2011). Vorlesungsaufzeichnung in der Mathematik Nutzung und Auswirkung auf die Studienleistung. DeLFI 2011 - Die 9. E-Learning Fachtagung Informatik, 163-172.

Zupancic, B., \& Horz, H. (2002). Lecture recording and its use in a traditional university course. Proceedings of the 7th Annual Conference on Innovation and Technology in Computer Science Education - ITiCSE'02, 24. http://doi.org/10.1145/544414.544424 


\section{AUTHORS' BIOGRAPHIES}

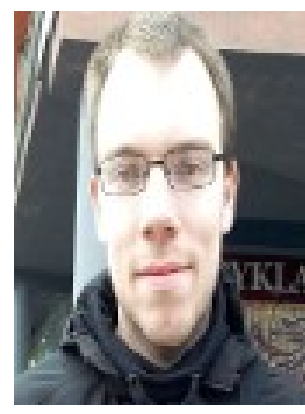

Daniel Ebbert is working in the lecture recording team at the University of Münster since December 2015 while finishing his Masters' degree in Technical Communication at the University of Twente. In July 2015 he obtained a Bachelor degree from the Saxion University of Applied Sciences in Information Services and Management. From August 2012 till June 2013 and from September 2014 till January 2015 he also worked as a Audio Video Technician for lecture recordings at the same University of Applied Sciences. In the time frame between those jobs he was doing a web development internship in Xiamen, China as part of his Bachelor program. He wrote his Bachelor thesis about information retrieval by foreign tourists in Lithuania and is currently writing his Master thesis on appropriation in learning management systems.

Linkedin: https://www.linkedin.com/in/debbert/ 